\title{
Beneficial influence of an indigenous low-iron diet on serum indicators of iron status in patients with chronic liver disease
}

\author{
Neelu Tandon, Varsha Thakur, Raj Kumar C. Guptan and Shiv K. Sarin* \\ Department of Gastroenterology, G.B. Pant Hospital, New Delhi, India
}

(Received 22 September 1998 - Revised 28 June 1999 - Accepted 18 August 1999)

\begin{abstract}
The main Fe storage organ in the body is the liver. In patients with chronic liver disease, secondary Fe overload is common. Phlebotomy, often used in the West to reduce Fe overload to improve the efficacy of interferon therapy, is not socially acceptable in India. We assessed the efficacy of a low-Fe diet in reducing serum Fe levels. Nineteen patients with hepatitis B- and C-related chronic liver disease, ten with normal $(<25 \mu \mathrm{mol} / \mathrm{l})$ baseline serum Fe levels (group A) and nine with high $(>25 \mu \mathrm{mol} / \mathrm{l})$ serum Fe levels (group B) were included. All the subjects were advised to eat a low-Fe diet. The daily Fe intake was reduced approximately $50 \%$ by consumption of the rice-based diet. Haemoglobin, serum Fe, transferrin saturation index (TSI), ferritin and alanine transaminase (EC 2.6.1.2) levels were studied at 1 and 4 months. Dietary Fe intake and body weight were closely monitored. All patients complied with the dietary regimen and at 4 months significant $(P<0.001)$ reductions from baseline were seen in serum Fe (20 (SD 3) v. 12 (SD 4) $\mu \mathrm{mol} / 1$ group A; 30 (SD 3) $v .19$ (SD 7) $\mu \mathrm{mol} / 1$ group B) and TSI (38 (SD 8) v. 23 (SD 9) \% group A; 53 (SD 15) v. 34 (SD 13) \%, group B) in both the groups, albeit earlier in group B subjects. Serum ferritin levels, however, reduced only in group A (112 (SD 62) v. 43 (SD 25) ng/ml, $P<0.05$ ) and not in group B. Non-significant reductions in haemoglobin levels were seen in both groups. Alanine transaminase levels reduced significantly $(P<0.05)$ in both the groups (95 (SD 49) v. 44 (SD 25) IU/l, group A; 82 (SD 16) v. 51 (SD 14) IU/l group B). Thus, a low-Fe diet results in significant reductions in serum Fe and TSI levels, irrespective of baseline Fe levels. This diet should be evaluated to improve the efficacy of interferon therapy in patients with hepatitis B- and C-related chronic liver disease.
\end{abstract}

Iron: Haemochromatosis: Chronic liver disease

Fe participates in a wide range of biochemical pathways that govern cellular metabolism (Caraceni et al. 1994). Fe absorption is regulated via poorly understood mechanisms to maintain body Fe stores at optimum levels while keeping the risk of $\mathrm{Fe}$ toxicity to a minimum (Aisen et al. 1990; Ryan \& Aust, 1992). The liver is the major Fe storage organ of the body. Hence, a close association exists between Fe and liver disorders. Over the last 20 years, considerable evidence has accumulated that a pathogenetic link exists between the $\mathrm{Fe}$ content of the liver and viral hepatitis (Caraceni et al. 1994). Individuals with elevated serum Fe or ferritin levels are more likely to become carriers of the hepatitis B virus infection than are those with normal or low levels of these two markers of Fe metabolism (Senba et al. 1985). There is no effective physiological mechanism for the excretion of excess body Fe, hence increased ingestion or absorption of $\mathrm{Fe}$ would increase body $\mathrm{Fe}$ stores and hepatic injury (Halliday \& Powell, 1992). A reduction in Fe stores by phlebotomy could help improve patients with chronic hepatitis (Hayashi et al. 1994). However, phlebotomy, the commonly used method to reduce Fe overload, is not socially acceptable in many countries, including India. The finding that reduced Fe stores enhance the response rate to the antiviral therapies currently available, and the non-acceptability of phlebotomy in India, prompted us to study the feasibility and effect of using a low-Fe diet to reduce the Fe levels in patients with chronic liver disease.

\section{Materials and methods}

A total of nineteen patients with hepatitis $B$ virus and hepatitis $\mathrm{C}$ virus-related chronic liver disease were studied between June 1997 and April 1998. According to the baseline serum Fe levels, patients were divided into: group A, which included ten subjects with normal $(<25 \mu \mathrm{mol} / \mathrm{l})$ baseline serum Fe levels and group $\mathrm{B}$, which included nine subjects with high $(>25 \mu \mathrm{mol} / \mathrm{l})$ baseline serum Fe levels. 


\section{Inclusion criteria}

The specific inclusion criteria were: age between 18 and 70 years, positivity of hepatitis B surface antigen or antibody to hepatitis $\mathrm{C}$ virus in the serum (third generation enzyme immunoassay), biopsy-proven chronic liver disease and early compensated or mildly decompensated (i.e. Child's A or B stage) liver disease (Child \& Turcotte, 1969).

\section{Exclusion criteria}

Exclusion criteria included patients having evidence of chronic alcohol abuse, hypersplenism, haemolytic anaemia, antiviral therapy in the last 12 months, pregnancy, platelet count $<70000 / \mathrm{mm}^{3}$, leucocyte counts $<4000 / \mathrm{mm}^{3}$, systemic disease, cancer, human immunodeficiency virus infection, blood transfusion in the last 8 weeks, malnutrition, or suspected haemochromatosis.

\section{Methods}

Laboratory measurements. Serum samples for Fe studies were collected in a fasting state between 09.00 and 10.00 hours and were stored at $-80^{\circ}$. The $\mathrm{Fe}$ variables were determined within 1 week of collection of the blood sample. Deionized water was used to avoid a false positive increase in the Fe levels.

Serum Fe, total Fe-binding capacity, ferritin and haemoglobin levels were measured before the initiation of the low-Fe diet, 1 month after starting the therapy, and on completion of the therapy 4 months after the starting day. Biochemical profile included alanine transaminase ( $E C$ 2.6.1.2), aspartate transaminase (EC 2.6.1.1) and albumin estimation. Serum Fe and total Fe-binding capacity were measured colorimetrically using commercially available kits (Randox Laboratories Ltd., Ardmore, UK).

Serum ferritin was measured using an enzyme immunoassay kit (Melotec Biotechnology, Barcelona, Spain). Transferrin saturation index (TSI) was calculated as $\mathrm{Fe} /$ total Fe-binding capacity $\times 100$. For analytical accuracy and precision, both normal and elevated assayed multisera, were run simultaneously along with test samples.

Hepatitis serology. The various markers of hepatitis B and $\mathrm{C}$ were studied using ELISA kits (Organon Teknika, Boxtel, The Netherlands). Hepatitis B virus DNA was tested both by dot blot hybridization as well as by polymerase chain reaction.

Low-iron diet. The normal Indian diet is primarily a wheat-based vegetarian diet, the Fe content of which is approximately $20 \mathrm{mg} / \mathrm{d}$. The dietary allowance for $\mathrm{Fe}$, as recommended by the Indian Council of Medical Research is about $28 \mathrm{mg} / \mathrm{d}$ for males and about $30 \mathrm{mg} / \mathrm{d}$ for females (Gopalan et al. 1989). In our specially formulated diet, we decreased the Fe content of the diet to about $6.7 \mathrm{mg} / \mathrm{d}$, without compromising the energy and protein content of the diet. This diet was primarily rice-based with casein as the main protein source. It contained the daily allowances for all food groups except for pulses and meat. Table 1 shows the food composition, energy, protein and $\mathrm{Fe}$ contents of the low-Fe diet. The diet had limited natural ascorbic acid.
Table 1. Composition of the low-iron diet used in the present study*

\begin{tabular}{lcccc}
\hline Foodstuff & Amount & $\begin{array}{c}\text { Energy } \\
(\mathrm{kJ})\end{array}$ & $\begin{array}{c}\text { Protein } \\
(\mathrm{g})\end{array}$ & $\begin{array}{c}\text { Iron } \\
(\mathrm{mg})\end{array}$ \\
\hline Milk & $500 \mathrm{ml}$ & 2448 & 21.5 & 1.0 \\
Curd & $300 \mathrm{~g}$ & 753 & 18.6 & 0.6 \\
Rice (raw) & $200 \mathrm{~g}$ & 2887 & 13.6 & 1.4 \\
Wheat (raw) & $25 \mathrm{~g}$ & 356 & 3.0 & 1.2 \\
Vegetables & $250 \mathrm{~g}$ & 418 & 2.5 & 1.5 \\
Potato & $100 \mathrm{~g}$ & 406 & 1.6 & 0.5 \\
Fruit & $100 \mathrm{~g}$ & 167 & 2.0 & 0.5 \\
Oil & $40 \mathrm{~g}$ & 1506 & - & - \\
Sugar & $30 \mathrm{~g}$ & 502 & - & - \\
Total & & 9443 & 62.8 & 6.7 \\
\hline
\end{tabular}

*Advice was given to avoid iron vessels for cooking, green leafy vegetables, citrus fruits with meals and pulses.

Dietary iron assessment. The $72 \mathrm{~h}$ dietary record method was used to assess the daily intake of Fe, whereby the subjects were asked to record all that they consumed for two working days and one non-working day. The diet was assessed before enrolling any patient for the study. A foodfrequency checklist consisting of Fe-rich foods commonly consumed by our population was also used to enhance the knowledge about Fe intake. The Fe content of food was determined according to the food tables from the National Institute of Nutrition, Hyderabad, India (Gopalan et al. 1989).

Assessment of body weight. The body weight of each subject was recorded before enrollment in the study. The measurement was done using a platform beam balance, without excessive clothing and shoes. In patients with ascites, the weight was recorded only after the patient reached the near dry weight state. Only the subjects with $90 \%$ of the ideal weight were included in the study, to avoid including any malnourished or underweight subjects.

\section{Statistical analysis}

The various observations are expressed as means and standard deviations. Within-group comparisons were made by using Student's $t$ test. Significance criteria of $P<0.001$ or $P<0.05$ were used for all inferences.

\section{Results}

\section{Demographic profile and dietary iron intake}

The two groups were comparable in age (38.5 (SD 13.6) v. 38.6 (SD 11.3) years). Group A included both male ( $n$ 6) and female $(n 4)$ patients whereas there were no female patients in group B. The baseline daily dietary Fe intakes of the subjects in the two groups were comparable (12.4 (SD 3.6) v. $10 \cdot 8(\mathrm{SD} 2 \cdot 5) \mathrm{mg})$.

\section{Body weight assessment}

The mean body weights for the two groups of subjects were similar (65 (SD 9) v. 69 (SD 12) kg) before initiation in the study. No patient had overt malnutrition as only subjects with Child's A or B stage liver disease were included. No significant change in weight after completion of the therapy was seen in any of the subjects included in the study. 
Table 2. Serum iron concentration, transferrin saturation index (TSI), ferritin and haemoglobin levels in two groups of patients with chronic liver disease $\dagger$ after 0,1 and 4 months on a low-iron dietł

(Mean values and standard deviations)

\begin{tabular}{|c|c|c|c|c|c|c|c|c|c|c|c|c|}
\hline \multirow[b]{3}{*}{ Variable } & \multicolumn{6}{|c|}{ Group A ( $n$ 10) } & \multicolumn{6}{|c|}{ Group B $(n 9)$} \\
\hline & \multicolumn{2}{|c|}{0 months } & \multicolumn{2}{|c|}{1 month } & \multicolumn{2}{|c|}{4 months } & \multicolumn{2}{|c|}{0 months } & \multicolumn{2}{|c|}{1 month } & \multicolumn{2}{|c|}{4 months } \\
\hline & Mean & SD & Mean & SD & Mean & SD & Mean & SD & Mean & SD & Mean & SD \\
\hline Serum iron $(\mu \mathrm{mol} / \mathrm{l})$ & 20 & 3 & 17 & 5 & $12^{\star \star \star}$ & 4 & 30 & 3 & $20^{\star * *}$ & 5 & $19^{* * *}$ & 7 \\
\hline TSI (\%) & 38 & 8 & 32 & 20 & $23^{\star \star *}$ & 9 & 53 & 15 & 46 & 17 & $34^{*}$ & 13 \\
\hline Ferritin (ng/ml) & 112 & 62 & 79 & 59 & $43^{*}$ & 25 & 114 & 44 & 118 & 63 & 93 & 59 \\
\hline Haemoglobin $(\mathrm{g} / \mathrm{l})$ & 140 & 18 & 135 & 20 & 127 & 20 & 136 & 26 & 129 & 21 & 124 & 17 \\
\hline
\end{tabular}

Mean values were significantly different from those for 0 months: ${ }^{*} P<0.05,{ }^{* *} P<0.001$ (Student's $t$ test).

† Group A had normal baseline serum Fe levels $(<25 \mu \mathrm{mol} / \mathrm{l})$, group B had high baseline serum Fe levels $(>25 \mu \mathrm{mol} / \mathrm{l})$. $\ddagger$ For details of the diet, see Table 1 .

\section{Iron studies}

The patients were divided into two groups based on the baseline serum Fe levels. Keeping these baseline Fe intake levels as the reference point, our low-Fe diet would have provided $54 \%$ and $62 \%$ of the usual daily intake for patients in groups $\mathrm{A}$ and $\mathrm{B}$ respectively. The mean serum Fe level of group A subjects was 20 (SD 3) $\mu \mathrm{mol} / \mathrm{l}$ while that of group B subjects was 30 (SD 3) $\mu \mathrm{mol} / \mathrm{l}$. All the subjects included in the study completed 4 months on the low-Fe diet. Significant $(P<0.001)$ reductions were seen in the two groups in both serum Fe levels (20 (SD 3) v. 12 (SD 4) $\mu \mathrm{mol} / \mathrm{l}$, group A; $30(\mathrm{SD} 3) v .19(\mathrm{SD} 7) \mu \mathrm{mol} / \mathrm{l}$, group B) and TSI (38 (SD 8) $v$. 23 (SD 9), group A; 53 (SD 15) v. 34 (SD 13), group B) after completion of the study (Table 2). Group B subjects showed a significant $(P<0.001)$ reduction in serum Fe levels within 1 month of starting the therapy compared with group A subjects for whom a slight reduction was seen. The percentage reductions in serum Fe (group A, 39 (SD 20) v. group B, 37 (SD 23)) and TSI (group A, 41 (SD 20) $v$. group B, 42 (SD $23)$ ) in the two groups were similar, after completion of 4 months on the low-Fe diet.

\section{Ferritin studies}

A significant reduction was seen in serum ferritin levels in group A subjects (112 (SD 62) v. 43 (SD 25) ng/ml, $P<0.05)$ (Table 2) but not in group B subjects (114 (SD 44) v. 93 (SD 59) $\mathrm{ng} / \mathrm{ml}$ ). A slight reduction of $12 \%$ was seen in the haemoglobin levels in both groups. However, the difference from the baseline was not significant. The percentage reduction in serum ferritin levels in group A subjects was 50 (SD 22).

\section{Liver function tests}

Significant reductions in the alanine transaminase levels were seen in both groups on completion of the diet therapy (group A, 95 (SD 49) v. 44 (SD 25) IU/1; group B, 82 (SD 16) v. 51 (SD 14) IU/l, $P<0 \cdot 05$ ). Reductions were also seen in the aspartate transaminase levels in both groups, although this was significant only in group A $(P<0.05)$ (Table 3$)$. The aspartate transaminase: ferritin value decreased from 1.66 to 1.0 in group A subjects and from 0.8 to 0.6 in group $B$ subjects. The albumin levels were well maintained in both group A (39 (SD 3) v. 40 (SD 3) g/l), and group B (38 (SD 6) $v$. 44 (SD 7) g/l) after completion of 4 months on the low-Fe diet suggesting adequacy of protein in the formulated diet.

\section{Discussion}

The results of the present study clearly demonstrate that a low-Fe diet substantially reduced the serum Fe levels and TSI in patients with chronic liver disease within 1 month of starting the therapy. This benefit increased further over 4 months. The reduction in Fe levels was seen earlier if the baseline serum Fe levels were high.

Table 3. Alanine transaminase, aspartate transaminase and albumin levels in two groups of patients with chronic liver disease $\nmid$ after 0 and 4 months on a low-iron dietf

(Mean values and standard deviations)

\begin{tabular}{|c|c|c|c|c|c|c|c|c|}
\hline \multirow[b]{3}{*}{ Variable } & \multicolumn{4}{|c|}{ Group A (n 10) } & \multicolumn{4}{|c|}{ Group B (n9) } \\
\hline & \multicolumn{2}{|c|}{0 months } & \multicolumn{2}{|c|}{4 months } & \multicolumn{2}{|c|}{0 months } & \multicolumn{2}{|c|}{4 months } \\
\hline & Mean & SD & Mean & SD & Mean & SD & Mean & SD \\
\hline Alanine transaminase (IU/I) & 95 & 49 & $44^{*}$ & 25 & 82 & 16 & $51^{*}$ & 14 \\
\hline Aspartate transaminase (IU/I) & 122 & 121 & $41^{*}$ & 21 & 66 & 6 & 60 & 22 \\
\hline Albumin $(\mathrm{g} / \mathrm{l})$ & 39 & 3 & 40 & 3 & 38 & 6 & 44 & 7 \\
\hline
\end{tabular}

Mean values were significantly different from those for 0 months, ${ }^{\star} P<0.05$.

† Group A had normal baseline serum Fe levels $(<25 \mu \mathrm{mol} / \mathrm{l})$, group B had high baseline serum Fe levels $(>25 \mu \mathrm{mol} / \mathrm{l})$. $\ddagger$ For details of the diet, see Table 1. 
In a study by Miller et al. (1997), dietary Fe was found to influence hepatic Fe content. The formulated low-Fe diet used in the present study would probably lead to a substantial reduction in the amount of $\mathrm{Fe}$ absorbed. This factor could also explain the quicker response seen in patients with a high baseline Fe level than those with a normal level.

Haem Fe can contribute a disproportionate $30 \%$ of the absorbed Fe due to its higher bioavailability compared with non-haem Fe. Diets based primarily on plants, owing to their exclusively non-haem Fe content, are considered to have low Fe bioavailability (Taylor et al. 1988). The bioavailability of non-haem Fe is markedly influenced by both Fe status (Taylor et al. 1988; Lynch et al. 1989; Hallberg et al. 1995) and meal composition (Hallberg, 1981). Absorption can vary from $2 \%$ from a meal containing inhibitors of non-haem Fe to $45 \%$ from a meal with enhancers (Hallberg, 1981). According to a report from the Food and Agriculture Organization/World Health Organization (1988), maximum absorption from this diet would average only $5-10 \%$ in $\mathrm{Fe}$ deficient individuals. It would probably be even lower in subjects, such as patients with liver disease, in whom $\mathrm{Fe}$ stores are loaded. Assuming an apparent absorption of 5$10 \%$, the Fe absorption from the low-Fe diet prescribed in the present study would only be about $0.3-0.7 \mathrm{mg} / \mathrm{d}$ whereas it would be about $0.6-1.2 \mathrm{mg} / \mathrm{d}$ from the actual basal intake of our subjects. This amounts to a reduction of about $40 \%$ in the amount of dietary Fe absorbed. In the West, reduction of serum $\mathrm{Fe}$ and ferritin levels is generally accomplished by performing weekly or biweekly phlebotomies. One unit of whole blood contains $250 \mathrm{mg}$ of Fe. Patients with $10-20 \mathrm{~g}$ excess Fe require phlebotomy of 40-80 units. Reaccumulation of Fe varies among individuals and some may require regular phlebotomy for many years (Bacon \& Britton, 1997). Assuming that fractional Fe absorption (5\%) is not influenced by the dietary modifications in this study, the amount of absorbed Fe can be estimated to be reduced from about $0.6 \mathrm{mg} / \mathrm{d}$ to about $0.3 \mathrm{mg} / \mathrm{d}$. During 4 months of low dietary $\mathrm{Fe}$ intake, the reduction in the total amount of $\mathrm{Fe}$ absorbed could be expected to be about $36 \mathrm{mg}$. The benefits of this approach were evident, as there was a $40 \%$ reduction in serum $\mathrm{Fe}$ and a $45 \%$ reduction in TSI on the low-Fe diet at 4 months. A reduction was also seen in the haemoglobin level, although it was not significant. A period of longer than 4 months may prove to achieve a significant reduction in haemoglobin levels as well. Though the effect of the diet is smaller and slower than that of phlebotomy, this method of lowering the Fe levels would be more acceptable in countries with cultural backgrounds like that of India.

Although a significant reduction of nearly $50 \%$ was seen in ferritin levels in group A subjects, the levels did not reduce significantly in group $\mathrm{B}$. This could be attributed to the 'flare' phenomenon seen in two group B patients. These two patients lost their replicative hepatitis B virus status (hepatitis B e antigen became negative and antibody, anti$\mathrm{HBe}$ (antibody to hepatitis B e antigen) developed, called 'seroconversion'). This beneficial effect was evident by enhanced inflammation and activity, called 'flare'. The ferritin as well as the transaminase levels increased. The ratio aspartate transaminase:ferritin is usually calculated in such patients to subdue the influence of such a flare. In our patients, while the ferritin levels did not come down, the aspartate transaminase:ferritin value decreased in both groups.

There is some evidence to suggest that a low-Fe diet alone, or as an adjunct to other therapies, could be beneficial to patients with chronic viral hepatitis. In a preliminary trial, the low-Fe diet improved the efficacy of interferon therapy in patients with chronic hepatitis B-related liver disease (Guptan et al. 1994). In the present study also a significant fall was observed in the alanine transaminase levels with a decrease in Fe variables. Further, two patients seroconverted to anti-HBe status.

A high compliance with the low-Fe diet was obtained from all the patients who were included in the trial. The diet provided adequate energy and protein to prevent any weight loss or deficiency. The protein content of the diet was in the form of casein, a preferred form of protein in liver disease patients, and was provided in quantities sufficient to meet the bodily requirements. No subject complained of any intolerance to this diet. The food items included in the diet were inexpensive, easily available and commonly consumed. These factors possibly added to the acceptability of the diet.

In conclusion, the results of this prospective study, carried out in patients with chronic liver disease clearly indicate that significant reductions can be obtained in serum Fe and TSI levels with a carefully monitored low-Fe diet within 4 months. If followed strictly, this diet may be a costeffective substitute for phlebotomy and may also have an important role in the management of chronic liver disease in patients with underlying Fe overload.

\section{References}

Aisen P, Cohen G \& Kang Jo (1990) Iron toxicosis. International Reviews in Experimental Pathology 31, 1-46.

Bacon BR \& Britton RS (1997) Hereditary hemochromatosis. In Sleisenger and Fordtran's Gastrointestinal and Liver Disease, pp. 1097-1103 [M Feldman, BF Scharschmidt and MH Sleisenger, editors]. Philadelphia, PA: W.B. Saunders Co.

Caraceni P, Fagiuoli S \& Van Thiel DH (1994) Iron reduction therapy: simply camouflage, or a real weapon? (Editorial). American Journal of Gastroenterology 89, 970-973.

Child CG III \& Turcotte JG (1969) Surgery of portal hypertension. In The Liver and Portal Hypertension, p. 50 [CG Child III, editor]. Philadelphia, PA: W.B. Saunders Co.

Food and Agriculture Organization/World Health Organization (1988) FAO/WHO Joint Expert Consultation Report. Requirement of Vitamin A, Iron, Folate and Vitamin B 12. Food and Nutrition Series no. 23. Rome: FAO.

Gopalan C, Rama Sastri BV \& Balasubramanian SC (1989) Nutritive Value of Indian Foods. Hyderabad: National Institute of Nutrition, Indian Council of Medical Research.

Guptan RC, Malhotra S, Khandekar P \& Sarin SK (1994) Influence of low iron diet on the efficacy of interferon therapy in patients with chronic liver disease. Indian Journal of Gastroenterology 13, W9.

Hallberg L (1981) Bioavailability of dietary iron in man. Annual Reviews in Nutrition 1, 123-147.

Hallberg L, Hulten L, Bengtsson C, Lapidus L \& Lindstedt G (1995) Iron balance in menstruating women. European Journal of Clinical Nutrition 49, 200-207. 
Halliday JW \& Powell LW (1992) Hemochromatosis and other diseases associated with iron overload. In Iron and Human Disease, pp. 132-160 [RB Lauffer, editor]. Boca Raton, FL: CRC Press.

Hayashi H, Takikawa T, Nishimura N, Yano M, Isomura T \& Sakamoto N (1994) Improvement of serum aminotransferase levels after phlebotomy in patients with chronic active hepatitis $\mathrm{C}$ and excess hepatic iron. American Journal of Gastroenterology 89, 986-988.

Lynch SR, Skikne BS \& Cook JD (1989) Food iron absorption in idiopathic hemochromatosis. Blood 74, 2187-2193.

Miller GF, Barnard DE, Woodward RA, Flynn BM \& Bulte JW (1997) Hepatic hemosiderosis in common marmosets, Callithrix jacchus: effect of diet on incidence and severity. Laboratory Animal Sciences 47, 138-142.

Ryan TP \& Aust SD (1992) The role of iron in oxygen mediated toxicities. Critical Reviews in Toxicology 22, 119-141.

Senba M, Nakamura T \& Itakura H (1985) Statistical analysis of relationship between iron accumulation and hepatitis B surface antigen. American Journal of Clinical Pathology 84, 340342.

Taylor P, Martinez-Torres C, Leets I, Ramirez J, Garciacasal MN \& Layrisse M (1988) Relationships among iron absorption, percent saturation of plasma transferrin and serum ferritin concentrations in humans. Journal of Nutrition 118, 11101115 . 